\title{
А.А. Рукавишникова
}

\section{ВИДЫ РЕШЕНИЙ, ПРИНИМАЕМЫХ СУДОМ В ПОРЯДКЕ ГЛ. 51.1 УПК РФ: ВОЗМОЖНОСТЬ ЗЛОУПОТРЕБЛЕНИЯ ДИСКРЕЦИОННЫМИ ПОЛНОМОЧИЯМИ ${ }^{1}$}

\begin{abstract}
Рассматриваются виды промежуточных и итоговых решений, принимаемых судом в порядке гл. 51.1 УПК РФ. Отмечается, что в УПК РФ в большинстве случаев не закреплены основания принятия судом этих решений. Некоторые основания разъяснены в постановлении Пленума Верховного Суда от 29.11.2016 г. № 56. Аргументируется, что отсутствие легальных оснований принятия судом решений затрудняет возможность принятия мотивированного решения, создает предпосылки для злоупотребления судьей дискреционными полномочиями и вынесения произвольных решений.

Ключевые слова: промежуточные и итоговые решения, критерии принятия решения, дискречионные полномочия, злоупотребления.
\end{abstract}

УПК РФ закрепил новый вид производства - производство о назначении меры уголовно-правового характера при освобождении от уголовной ответственности, которое в процессуальной литературе называют новым видом основного производства [1. С. 370]. В ходе реализации норм гл. 51.1 УПК РФ, предусматривающих порядок о прекращении уголовного дела или уголовного преследования и назначении лицу меры уголовно-правового характера в виде судебного штрафа, на основании ч. 5 ст. 446.2 УПК РФ могут быть приняты следующие виды решений: во-первых, итоговые - постановление об удовлетворении ходатайства о прекращении уголовного дела или уголовного преследования по основаниям, предусмотренным ст. 25.1 УПК РФ и назначении лицу меры уголовно-правового характера в виде судебного штрафа, и постановление об отказе в удовлетворении ходатайства о прекращении уголовного дела или уголовного преследования и назначении лицу меры уголовно-правового характера в виде судебного штрафа с возвращением ходатайства и материалов уголовного дела руководителю следственного органа или прокурору.

В качестве итоговых данные решения названы в п. 18 (п. 25.3) Постановления Пленума Верховного Суда РФ от 29.11.2016 № 56 [2]. Вместе с тем учитывая, что постановление об удовлетворении ходатайства о прекращении уголовного дела или уголовного преследования по основаниям, предусмотренным ст. 25.1 УПК РФ, и назначении лицу меры уголовно-правового характера в виде судебного штрафа может быть отменено в порядке ст. 446.5 УПК РФ, самим судом, его вынесшим (в порядке так называемого самоконтроля), то такое решение можно назвать итоговым под условием. Представ-

\footnotetext{
${ }^{1}$ Исследование подготовлено при финансовой поддержке научно-исследовательского проекта РГНФ № 16-03-00413.
} 
ляется, что таковым оно может стать только при условии выполнения возложенной на лицо обязанности - уплаты штрафа.

В соответствии с ч. 1 ст. 446.3 УПК РФ если в ходе судебного производства по уголовному делу будут установлены основания, предусмотренные ст. 25.1 УПК РФ, суд выносит постановление или определение о прекращении уголовного дела или уголовного преследования и о назначении подсудимому меры уголовно-правового характера в виде судебного штрафа, в котором указывает размер судебного штрафа, порядок и срок его уплаты. Такое решение в соответствии со ст. 25.1 УПК РФ может быть принято как судом по собственной инициативе, так и по результатам рассмотрения ходатайства, поданного следователем с согласия руководителя следственного органа либо дознавателем с согласия прокурора.

На основании ст. 25.1 УПК РФ в решении должны быть установлены следующие обстоятельства: лицо подозревается или обвиняется в совершении преступления небольшой или средней тяжести, это лицо возместило ущерб или иным образом загладило причиненный преступлением вред. Исходя из требований ст. 446.2 УПК РФ, в решении суда необходимо также отразить согласие подозреваемого, обвиняемого на прекращение уголовного дела в порядке ст. 25.1 УПК РФ. Кроме того, при определении размера и срока уплаты штрафа устанавливается также материальное положение подозреваемого (обвиняемого). Больше никаких требований к выносимому решению УПК РФ не содержит.

Между тем в соответствии с п. 18 (п. 25.5) Постановления Пленума Верховного Суда РФ от 29.11.2016 № 56 установлено, что судья принимает решение об удовлетворении ходатайства при отсутствии обстоятельств, препятствующих освобождению лица от уголовной ответственности, и назначении ему меры уголовно-правового характера в виде судебного штрафа. К таковым могут быть отнесены, в частности, следующие обстоятельства: подозреваемый, обвиняемый не подтвердил в судебном заседании свое согласие на прекращение уголовного дела или уголовного преследования по данному основанию; сведения об участии подозреваемого, обвиняемого в совершенном преступлении, изложенные в постановлении о возбуждении ходатайства о применении к нему меры уголовно-правового характера в виде судебного штрафа, не соответствуют фактическим обстоятельствам дела; наличие иных оснований прекращения уголовного дела или уголовного преследования, например, отсутствие события или состава преступления, истечение срока давности уголовного преследования (п. 2 ч. 5 ст. 446.2 УПК РФ) [2]. Кроме того, к числу таких оснований могут быть отнесены сведения о том, что подозреваемый, обвиняемый возместил ущерб или иным образом загладил причиненный преступлением вред, не нашли подтверждения в судебном заседании.

Исходя из анализа норм УПК РФ и положений Постановления Пленума Верховного Суда РФ от 29.11.2016 № 56, можно сделать вывод, что к решениям, принимаемым по итогам судебного заседания в порядке гл. 51.1 УПК РФ, в равной мере (как, например, и к приговору) предъявляются требования законности, обоснованности и справедливости (в контексте размера штрафа). Это косвенно подтверждается и тем, что для этого вида решений предусмотрен общий порядок апелляционного обжалования. 
УПК РФ не расшифровывает категорию обоснованности применительно к этому виду итогового решения. Вместе с тем в соответствии с п. 18 (25.3) Постановления Пленума Верховного Суда РФ от 29.11.2016 № 56 предусмотрено, что суд при вынесении постановления должен прийти к убеждению, что выдвинутое в отношении лица подозрение или предъявленное лицу обвинение в совершении преступления небольшой или средней тяжести обоснованно, подтверждается доказательствами, собранными по уголовному делу, и в материалах содержатся достаточные сведения, позволяющие суду принять итоговое решение о прекращении уголовного дела или уголовного преследования и назначении подозреваемому, обвиняемому меры уголовноправового характера в виде судебного штрафа [2].

При разъяснении требований, предъявляемых к описательномотивировочной части постановления, Пленум Верховного Суда РФ установил, что в описательно-мотивировочной части постановления судьи об удовлетворении ходатайства о прекращении уголовного дела или уголовного преследования и назначении лицу меры уголовно-правового характера в виде судебного штрафа должны быть, в частности, приведены: описание преступного деяния, в совершении которого лицо подозревается или обвиняется, с указанием пункта, части, статьи Уголовного кодекса Российской Федерации; вывод о том, что выдвинутое в отношении лица подозрение или предъявленное лицу обвинение подтверждается доказательствами, собранными по уголовному делу [2]. А к числу оснований, препятствующих вынесению постановления об удовлетворении соответствующего ходатайства следователя (дознавателя), установлено такое, как несоответствие сведений об участии подозреваемого, обвиняемого в совершенном преступлении, изложенных в постановлении о возбуждении ходатайства, фактическим обстоятельствам дела.

Вполне закономерно возникает вопрос, каковы пределы обоснованности подозрения и обвинения в совершении преступления при рассмотрении судом ходатайства о прекращении уголовного дела или уголовного преследования и назначении лицу меры уголовно-правового характера в виде судебного штрафа. Если попытка дать понятие обоснованного подозрения сделана в Постановлении Пленума Верховного Суда РФ от 19 декабря 2013 г. № 41, в соответствии с п. 2 которого под ним понимается наличие данных о том, что это лицо причастно к совершенному преступлению (застигнуто при совершении преступления или непосредственно после его совершения; потерпевший или очевидцы указали на данное лицо как на совершившее преступление; на данном лице или его одежде, при нем или в его жилище обнаружены явные следы преступления и т.п.) [3], то что означает обоснованное обвинение в контексте осуществления правосудия и презумпции невиновности, в актах толкования не разъяснено. В уголовно-процессуальной литературе на основе анализа норм УПК РФ (ст. 25.1 гл. 51.1) делается обоснованный вывод о том, что данные положения закона означают, что в ходе решения вопроса о назначении лицу меры уголовно-правового характера в виде судебного штрафа происходит установление и признание того факта, что возникло уголовноправовое отношение (совершено преступление) и что преступление совершено лицом, в отношении которого решается вопрос о назначении судебного 
штрафа, т.е. в положительной форме разрешается вопрос о его виновности в совершении уголовного преступления [1. С. 369]. В связи с этим уровень обоснованности, в том числе в части признания виновности лица в совершении преступления, в постановлении судьи о прекращении уголовного дела должен быть приближен к обвинительному приговору. Однако рекомендованная к использованию процессуальная форма, предусмотренная ст. 108 УПК РФ, вряд ли способна обеспечить такой ее высокий уровень.

УПК РФ не регламентирует основания принятия решения об отказе в удовлетворении ходатайства следователя (дознавателя). Однако в п. 18 (п. 25.5) Постановления Пленума Верховного Суда РФ от 29.11.2016 № 56 [2] установлено, что в случае отказа в удовлетворении ходатайства в постановлении судьи должны быть приведены конкретные мотивы и основания принятого решения. Это необходимо для того, чтобы такое решение не носило произвольный характер. В числе таких оснований могут выступать те же основания, что и для отказа в рассмотрении ходатайства (если они были уже выявлены в ходе судебного разбирательства), а также случаи неподтверждения (или недостаточного подтверждения) тех обстоятельств, которые указаны в ст. 25.1 УПК РФ.

Рассматривая промежуточные решения, следует отметить, что УПК РФ к возможному промежуточному решению отнес лишь одно - решение об отмене постановления о прекращении уголовного дела или уголовного преследования и назначении меры уголовно-правового характера в виде судебного штрафа принимается на основании представления судебного приставаисполнителя судом, к подсудности которого относится уголовное дело, принимаемое в порядке ст. 446.5 УПК РФ. Вместе с тем в соответствии с Постановлением Пленума Верховного Суда РФ от 29.11.2016 № 56 (п. 18 (25.2)) при производстве в порядке гл. 51.1 УПК РФ суд может принять еще один вид промежуточного решения - решение об отказе в принятии ходатайства к рассмотрению и возвращению вместе с материалами уголовного дела руководителю следственного органа или прокурору [2].

Закрепляя такие виды решений, законодатель между тем не всегда последовательно определяет основания принятия их судом. В некоторых случаях основания принятия таких решений в УПК РФ вообще не определены, что создает предпосылку для возможного злоупотребления дискреционными полномочиями при их принятии, под которым понимается явление, представляющее собой осуществление по своему усмотрению предоставленных законом возможностей в противоречии с их назначением, замыслом законодателя, в результате которого причиняется вред правам и законным интересам иных участников уголовного процесса и интересам правосудия в целом либо возникает опасность причинения такого вреда [4. С. 559].

Между тем Конституционный Суд РФ отмечал, что неопределенность содержания правовой нормы допускает возможность неограниченного усмотрения в процессе правоприменения и неизбежно ведет к произволу, а значит, к нарушению принципов равенства, а также верховенства закона. Именно отсутствие возможности произвольного применения содержания нормы, юридических понятий, институтов является гарантией такого естественного права человека, как право на правовую определенность, а также право на рав- 
ное отношение при реализации прав и свобод человека и гражданина [5]. Конституционный Суд РФ, обобщая дефекты нормотворческой деятельности, указывает на то, что нарушение в процессе законотворчества как на федеральном, так и на региональном уровне основополагающих принципов правового регулирования с неизбежностью ведет к появлению различного рода дефектов нормотворчества (недостатки систематизации, фрагментарность, коллизионность, юридико-технические недочеты), нередко оборачивается неконституционностью нормативного регулирования, а также значительно увеличивает риски неконституционного правоприменения - применения нормы в смысле, расходящемся с конституционным [6].

Существование дискреционных полномочий при регламентации компетенции суда вполне допустимо. Они обеспечивают независимость судебной власти и позволяют выбрать наиболее эффективный вариант правового регулирования в конкретной ситуации. Однако дискреция всегда создает и возможность для злоупотребления полномочиями. Поэтому Конституционный Суд РФ, признавая возможность (а иногда и нужность) существования такого способа нормативного регулирования, как предоставление дискреционных полномочий, подчеркивает необходимость в этих случаях установления четких, определенных критериев и порядка применения такой дискреции, как гарантии от злоупотребления и произвольного применения [6].

Одним из видов промежуточных решений суда, которое может быть вынесено в порядке гл. 51.1 УПК РФ, является решение об отмене постановления о прекращении уголовного дела или уголовного преследования и назначении меры уголовно-правового характера в виде судебного штрафа и направление материалов руководителю следственного органа или прокурору. В соответствии со ст. 446.5 УПК РФ в случае неуплаты лицом судебного штрафа, назначенного в качестве меры уголовно-правового характера, суд по представлению судебного пристава-исполнителя в порядке, установленном ч. 2, 3, 67 ст. 399 УПК РФ, отменяет постановление о прекращении уголовного дела или уголовного преследования и назначении меры уголовноправового характера в виде судебного штрафа и направляет материалы руководителю следственного органа или прокурору. Направление материалов вышеуказанным должностным лицам необходимо для подготовки уголовного дела к рассмотрению в общем порядке. Дальнейшее производство по уголовному делу осуществляется в общем порядке.

Пленум Верховного Суда РФ, разъясняя норму ст. 446.5 УПК РФ, в ч. 4 п. 21.1 Постановления отмечает, что решение об отмене постановления о прекращении уголовного дела или уголовного преследования и назначении меры уголовно-правового характера в виде судебного штрафа принимается на основании представления судебного пристава-исполнителя судом, к подсудности которого относится уголовное дело [2].

В соответствии с ч. 2 ст. 463.2 УПК РФ лицо, в отношении которого вынесено решение о прекращении уголовного дела или уголовного преследования и назначении меры уголовно-правового характера в виде судебного штрафа, обязано предоставить информацию об уплате судебного штрафа судебному приставу-исполнителю в течение 10 дней после истечения срока, установленного для уплаты судебного штрафа. УПК РФ не детализирует спо- 
соб предоставления такой информации. При отсутствии этой информации судебный пристав возбуждает соответствующее ходатайство. УПК РФ не содержит требований, предъявляемых к данному ходатайству, но, исходя из общих положений, оно должно быть законным и обоснованным.

Исходя из анализа норм УПК РФ, можно сделать вывод, что для принятия решения судом необходимо одно-единственное основание - неуплата штрафа в срок, установленный в решении. Кроме того, в ч. 4 п. 21.2 Постановления Пленума Верховного Суда РФ от 29.11.2016 № 56 указано на то, что уголовно-процессуальным законом не предусмотрены: продление срока исполнения решения о применении меры уголовно-правового характера в виде судебного штрафа, а также отсрочка или рассрочка исполнения такого решения [2]. Однако в п. 14 данного решения Верховного Суда РФ указано на то, что с учетом положений ч. 2 ст. 104.4 УК РФ лицо считается уклоняющимся от уплаты судебного штрафа, назначенного в соответствии со ст. 76.2 УК РФ, если оно не уплатило такой штраф в установленный судом срок (до истечения указанной в постановлении суда конкретной даты) без уважительных причин. Уважительными причинами неуплаты судебного штрафа могут считаться такие появившиеся после вынесения постановления о прекращении уголовного дела или уголовного преследования обстоятельства, вследствие которых лицо лишено возможности выполнить соответствующие действия (например, нахождение на лечении в стационаре, утрата заработка или имущества ввиду обстоятельств, которые не зависели от этого лица) [2]. Соответственно основаниями для принятия решения судом является не только факт неуплаты штрафа в срок, но и отсутствие уважительных причин его неуплаты.

С учетом того, что суд может принять во внимание уважительный характер причины неуплаты штрафа в срок (всей суммы или в части) и отказать в удовлетворении представления судебного пристава, фактически такая отсрочка или рассрочка уплаты штрафом может быть предоставлена.

Кроме того, при отсутствии требований к представлению судебного пристава остаются непонятными основания возможного отказа в его удовлетворении со стороны суда. Представляется, что в качестве таковых могут выступать незаконность и необоснованность представления, в частности, при установлении уважительности причин неуплаты штрафа. Интересным является и вопрос о том, какое решение должен принять суд, если лицо выполнило обязанность по уплате штрафа уже после направления представления судебным приставом.

Рассматривая возможность и основания вынесения такого вида промежуточного решения, как постановление об отказе в принятии ходатайства, Пленум Верховного Суда РФ в своем решении от 29.11.2016 № 56 (п. 18 (п. 5.2)) разъяснил, что судья отказывает в принятии ходатайства к рассмотрению по следующим основаниям (их можно условно разделить на основания, проявляющиеся в незаконности, и основания, проявляющиеся в необоснованности): к первой группе относятся случаи, если оно составлено с нарушением требований уголовно-процессуального закона, что исключает возможность рассмотрения ходатайства и вынесения решения в соответствии сч. 5 ст. 446.2 УПК РФ (в частности, когда оно возбуждено без согласия подозреваемого, обвиняемого на прекращение уголовного дела или уголовного пре- 
следования по основанию, предусмотренному ст. 25.1 УПК РФ, или без соблюдения указанных в этой статье условий освобождения от уголовной ответственности, к примеру, лицо подозревается или обвиняется в совершении тяжкого преступления, у него имеется неснятая или непогашенная судимость); ко второй группе относятся случаи, когда ходатайство не содержит следующих сведений: описание преступного деяния, в совершении которого лицо подозревается или обвиняется, с указанием пункта, части, статьи УК РФ; доказательства, подтверждающие выдвинутое подозрение или предъявленное обвинение; основание для прекращения судом уголовного дела или уголовного преследования и назначения подозреваемому, обвиняемому меры уголовно-правового характера в виде судебного штрафа; указание о согласии подозреваемого, обвиняемого на прекращение уголовного дела или уголовного преследования по данному основанию; не приложены все материалы уголовного дела. Кроме того, основанием является также ситуация, когда уголовное преследование осуществляется в отношении нескольких подозреваемых или обвиняемых и имеются основания для прекращения уголовного дела или уголовного преследования с назначением меры уголовно-правового характера в виде судебного штрафа в отношении всех или некоторых из этих лиц, а в суд представлено одно ходатайство на всех лиц.

Представляется, что данный вид решений и основания его принятия должны быть отражены в процессуальном законе, иначе принятие такого решения носит произвольный характер в том смысле, который определяет Конституционный Суд РФ.

Согласно этим же разъяснениям Пленума Верховного Суда РФ постановление судьи об отказе в принятии ходатайства к рассмотрению может быть обжаловано в вышестоящий суд в апелляционном порядке, который установлен гл. 45.1 УПК РФ. Таким образом, законодатель не установил процессуальных особенностей обжалования данного вида промежуточного решения, определив для него общий порядок апелляционного обжалования.

Вопрос о необходимости закрепления возможности обжалования такого решения является весьма спорным. Анализ оснований, по которым суд принимает решение об отказе в рассмотрении ходатайства, показывает, что все они носят преодолимый (исправляемый) характер, а возникшее состояние процессуального «конфликта» между участниками уголовного процесса могло бы преодолеваться путем повторного предоставления такого ходатайства в срок, установленный судом в решении об отказе в его рассмотрении.

Но даже если признать необходимость апелляционного порядка обжалования данного решения, следовало бы учесть, что вышеуказанное ходатайство составляют профессиональные участники уголовного судопроизводства (следователь, дознаватель) под руководством руководителя следственного органа и прокурора, в связи с чем для проверки данного вида промежуточного решения в апелляционном порядке необходимо было бы установить более сокращенные сроки.

Кроме того, необходимо четко определить круг возможных субъектов обжалования (в частности, решить, могут ли в качестве таковых выступать следователи, дознаватели, а также руководитель следственного органа и прокурор, потерпевший). Если признавать это право за всеми участниками про- 
цесса, то не исключена ситуация конкуренции порядков, когда следователь (дознаватель) после исправления недостатков ходататйства повторно направит его в суд (хотя в вышеуказанном постановлении Пленума Верховного Суда РФ на это не указывается, но сам преодолимый (исправляемый) характер оснований отказа в рассмотрении ходатайства позволяет говорить о такой возможности), а другие участники процесса подадут на решение суда апелляционную жалобу.

Как уже было отмечено выше, в УПК РФ при регламентации прекращения уголовного дела или уголовного преследования по основаниям, предусмотренным ст. 25.1 УПК РФ, и назначении лицу меры уголовно-правового характера в виде судебного штрафа достаточно непоследовательно решен вопрос о способах, критериях, сроках, субъектах обжалования тех или иных итоговых или промежуточных решений. Между тем право на обжалование и определенные по своему содержанию основания такого обжалования представляют собой серьезную гарантию против злоупотребления судом своими дискреционными полномочиями и вынесения произвольных решений, о недопустимости принятия которых неоднократно отмечал Конституционный Суд РФ [7].

Наличие в процессуальном законе установленных с определенностью оснований принятия тех или иных решений, с одной стороны, демонстрирует для участников уголовно-процессуальных отношений допустимые мотивы принятия судом того или иного решения. Будучи отраженными и подтвержденными в конкретном решении суда, основания делают решение мотивированным и обоснованным и позволяют это решение оценить с позиции в том числе возможного злоупотребления дискреционными полномочиями со стороны суда. С другой стороны, определенность закона в этой части позволяет и самому правоприменителю в лице суда быть защищенным (при условии соблюдения этих норм закона) от возможной отмены принятого им решения.

Представляется, что во избежание возникновения ситуаций, связанных с возможным злоупотреблением дискреционными полномочиями суда при принятии решений в порядке гл. 51.1 УПК РФ, необходимо четко регламентировать в УПК РФ такой вид решения и основания его принятия, как решение об отказе в принятии ходатайства к рассмотрению и возвращению вместе с материалами уголовного дела руководителю следственного органа или прокурору, а также разрешить вопрос о возможности, границах и субъектах обжалования данного вида решения. Кроме того, разрешить вопрос о требованиях, предъявляемых к итоговым решениям, выносимых в порядке гл. 51.1 УПК РФ, а также определить границы и порядок их обжалования. Также нуждаются в процессуальном закреплении и основания принятия такого решения, как отмена постановления о прекращении уголовного дела или уголовного преследования и назначении меры уголовно-правового характера в виде судебного штрафа.

\section{Лumepamypa}

1. Трубникова T.B. Производство о назначении меры уголовно-правового характера в виде судебного штрафа: сущность и гарантии от злоупотребления правом // Современное уголовнопроцессуальное право России - уроки истории и проблемы дальнейшего реформирования: ме- 
ждународная науч.практ. конф. (2016 г., Орёл): [к 60-летию доктора юридических наук, профессора, заслуженного деятеля науки РФ В.В. Николюка: сб. материалов] / редкол. А.В. Гришин [и др.|; Орловский юридический институт МВД России им. В.В. Лукьянова. Орёл: ОрЮИ МВД России им. В.В. Лукьянова, 2016. 444 с.

2.0 внесении изменений в некоторые постановления Пленума Верховного Суда Российской Федерации по вопросам совершенствования оснований и порядка освобождения от уголовной ответственности: Постановление Пленума Верховного Суда РФ от 29.11.2016 № 56 [Электронный ресурс] // КонсультантПлюс: справ.-правовая система. Версия Проф, сетевая. Электрон. дан. (39 кб.). М.: АО «КонсультантПлюс», 1992. Режим доступа: Компьютер. сеть Науч. б-ки Том. гос. ун-та, свободный (дата обращения: 20.01.2016).

3. О практике применения судами законодательства о мерах пресечения в виде заключения под стражу, домашнего ареста и залога: Постановление Пленума Верховного Суда РФ от 19.12.2013 № 41 (ред. от 24.05.2016) [Электронный ресурс] // КонсультантПлюс: справ.правовая система. Версия Проф, сетевая. Электрон. дан. (39 кб.). М.: АО «КонсультантПлюс», 1992. Режим доступа: Компьютер. сеть Науч. б-ки Том.гос. ун-та, свободный (дата обращения: 20.01.2016).

4. Андреева О.И., Желева О.В., Рукавишникова А.А. Трубникова Т.В. Право на возвращение уголовного дела судом апелляционной инстанции в суд первой инстанции: возможность злоупотребления полномочиями // Всероссийский криминологический журнал. 2016. № 3. 662 с.

5. По делу о проверке конституционности отдельных положений Закона РСФСР «О Государственной налоговой службе РСФСР» и Законов Российской Федерации «Об основах налоговой системы в Российской Федерации» и «О федеральных органах налоговой полиции»: Постановление Конституционного Суда РФ от 15.07.1999 № 11-П [Электронный ресурс] // КонсультантПлюс: справ.-правовая система. Версия Проф, сетевая. Электрон. дан. (39 кб.). М.: АО «КонсультантПлюс», 1992. Режим доступа: Компьютер. сеть Науч. б-ки Том. гос. ун-та, свободный (дата обращения: 20.01.2016).

6. Конституционно-правовые аспекты совершенствования нормотворческой деятельности (на основе решений Конституционного Суда Российской Федерации 2013-2015 годов) / Информация: Решение Конституционного Суда РФ от 23.06.2016 [Электронный ресурс] // КонсультантПлюс: справ.-правовая система. Версия Проф, сетевая. Электрон. дан. (39 кб.). М.: АО «КонсультантПлюс», 1992. Режим доступа: Компьютер. сеть Науч. б-ки Том. гос. ун-та, свободный (дата обращения: 20.01.2016).

7. По делу о проверке конституционности ряда положений статей 401.3, 401.5, 401.8 и 401.17 Уголовно-процессуального кодекса Российской Федерации в связи с жалобами граждан С.С. Агаева, А.Ш. Бакаяна и др.: Постановление Конституционного Суда РФ от 25.03.2014 № 8-П [Электронный ресурс] // КонсультантПлюс: справ.-правовая система. Версия Проф, сетевая. Электр. дан. (39 кб.). М.: АО «КонсультантПлюс», 1992. Режим доступа: Компьютер. сеть Науч. б-ки Том. гос. ун-та, свободный (дата обращения: 20.01.2016).

Rukavishnikova Anastasia A. Tomsk State University (Tomsk, Russian Federation)

TYPES OF DECISIONS MADE BY COURT IN CHAPTER.51.1 OF THE CRIMINAL PROCEDURE CODE OF THE RUSSIAN FEDERATION: POSSIBILITY OF ABUSE OF DISCRETIONARY POWERS

Key words: intermediate and final decisions, criteria for decision-making, discretionary powers, abuses.

Within the proceedings provided in Chapter 51.1 of the Criminal Procedure Code of the Russian Federation the following types of decisions can be taken: total decisions (resolutions on satisfaction and on refusal in satisfaction of the petition for the termination of criminal case or criminal prosecution on the bases provided by Article 25.1 of the Criminal Procedure Code of the Russian Federation and imposition of a measure of criminal and legal character in the form of a judicial penalty) and intermediate ones (the decision on cancellation of the resolution on the termination of criminal case or criminal prosecution and imposition of a measure of criminal and legal character in the form of penalty). Moreover, in compliance with the Resolution of the Plenum of the Supreme Court 29.11.2016 N 56 (Item 18 (25.2)) during proceedings under Chapter.51.1 of the Criminal Procedure Code of the Russian Federation one more type of intermediate judgment is provided- the decision on refusal in acceptance of the petition and on its return together with the criminal case files to the head of investigative 
body or prosecutor. The analysis of norms of the Criminal Procedure Code of the Russian Federation shows that legislators, when fixing such types of decisions, not always consistently defines the bases for the acceptance of such norms by the court. In certain cases the bases of acceptance of such decisions in the Criminal Procedure Code of the Russian Federation are not defined and this creates a prerequisite for possible abuse of discretionary powers and, as a result, the awarding of arbitrary decisions. The author concludes that in order to avoid this, it is necessary to resolve a question of requirements imposed on final decisions and a procedural form of their acceptance; to regulate accurately in the Criminal Procedure Code of the Russian Federation such type of the decision as the one on refusal to accept the petition and return it together with the criminal case files to the head of an investigative body or the prosecutor, to resolve a question of an opportunity, limits and subjects of the appeal of this type of decisions. Moreover, the bases for acceptance of such decisions as cancellation of the resolution on the termination of criminal case or criminal prosecution and imposition of a measure of criminal and legal character in the form of judicial penalty or as refusal to satisfy the corresponding report of the bailiff need procedural fixing.

\section{References}

1. Trubnikova, T.V. (2016) Proizvodstvo o naznachenii mery ugolovno-pravovogo kharaktera v vide sudebnogo shtrafa: sushchnost' i garantii ot zloupotrebleniya pravom [The proceeding of the appointment of a measure of a criminal-legal nature in the form of a judicial penalty: the essence and guarantees against abuse of law]. In: Grishin, A.V. et al. (eds) Sovremennoe ugolovno-protsessual'noe pravo Rossii - uroki istorii i problemy dal'neyshego reformirovaniya [Contemporary criminal procedure law of Russia - Lessons of history and problems of further reform]. Orel: Orel Law Institute of the Ministry of the Interior of Russia.

2. Russian Federation. (2016) On amending some resolutions of the Plenum of the Supreme Court of the Russian Federation on the improvement of the grounds and procedure for exemption from criminal liability: Decree No. 56 of the Plenum of the Supreme Court of the Russian Federation of November 29, 2016. [Online] Available from: http://www.consultant.ru/ document/cons doc_LAW_207871/. (Accessed: 20th January 2016). (In Russian).

3. Russian Federation. (2016) On the practice of the courts applying legislation on preventive measures in the form of detention, home arrest and bail: Resolution No. 41 of the Plenum of the Supreme Court of the Russian Federation of December 19, 2013 (Edited on May 24, 2016). [Online] Available from: http://www.consultant.ru/document/cons_doc_LAW_156184/. (Accessed: 20th January 2016). (In Russian).

4. Andreeva, O.I., Zheleva, O.V., Rukavishnikova, A.A. \& Trubnikova, T.V. (2016) The court of appeal's right to return a criminal case to the first-instance court: a possibility of power abuse. Vserossiyskiy kriminologicheskiy zhurnal - Russian Journal of Criminology. 3(10). (In Russian). DOI: 10.17150/2500-4255.2016.10(3).554-567

5. Russian Federation. (1999) On verification of the constitutionality of certain provisions of the RSFSR Law "On the State Tax Service of the RSFSR" and the Laws of the Russian Federation "On the Basics of the Tax System in the Russian Federation" and "On Federal Tax Police Authorities": Resolution No. 11-П of the Constitutional Court of the Russian Federation of July 15, 1999. [Online] Available from: http://www.consultant.ru/document/cons_doc_LAW_23820/. (Accessed: 20th January 2016). (In Russian).

6. Russian Federation. (2016) Constitutional and legal aspects of improving norm-setting activities (on the basis of the decisions of the Constitutional Court of the Russian Federation 2013-2015) Information: Decision of the Constitutional Court of the Russian Federation of June 23, 2016. [Online] Available from: http://www.consultant.ru/document/cons_doc_LAW_201240/. (Accessed: 20th January 2016). (In Russian).

7. Russian Federation. (2014) On verification of the constitutionality of a number of provisions of Aarticles 401.3, 401.5, 401.8 and 401.17 of the Code of Criminal Procedure of the Russian Federation in connection with the complaints of citizens S.S. Agaev, A.Sh. Bakayan et al.: Decision No. 8-P of the Constitutional Court of the Russian Federation of March 25, 2014. [Online] Available from: http://www.consultant.ru/document/cons_doc_LAW_160813/. (Accessed: 20th January 2016). (In Russian). 